\title{
Ultrawideband Vivaldi Antenna for DVB-T, WLAN, and WiMAX Applications
}

\author{
Dalia M. Elsheakh and Esmat A. Abdallah \\ Microstrip Department, Electronics Research Institute, Giza 12622, Egypt \\ Correspondence should be addressed to Dalia M. Elsheakh; daliaelsheakh@gmail.com
}

Received 3 August 2013; Revised 25 November 2013; Accepted 26 November 2013; Published 5 February 2014

Academic Editor: Abdel Fattah Shetta

Copyright (C) 2014 D. M. Elsheakh and E. A. Abdallah. This is an open access article distributed under the Creative Commons Attribution License, which permits unrestricted use, distribution, and reproduction in any medium, provided the original work is properly cited.

\begin{abstract}
Compact Vivaldi patch antenna with a parasitic meander line is presented in this paper. A PIN diode switch is used to connect and disconnect ultrahigh frequency band (UHF) with ultrawide bandwidth (UWB). The operating frequencies can be switched among different services, depending on the switching states (ON/OFF) to add the lower band when required. This antenna is suitable for portable DVB-T which extended from $450 \mathrm{MHz}$ to $850 \mathrm{MHz}$ receiver applications and the WLAN (Wireless Local Area Network) IEEE 802.11b,g (5.1-5.8) GHz frequency bands and WiMAX band (3.3-3.8) GHz. The measured reflection coefficient of the proposed antenna is compared with the simulated one; good agreement is observed. Also, simulated radiation pattern of the antenna is presented. All simulations are carried out using the EM commercial simulator, high frequency structure simulator (HFSS) ver.13.
\end{abstract}

\section{Introduction}

The rapid developments in broadband wireless communications and the great number of commercial and military applications necessitate new types of antennas which can support higher bit rates. 4G mobile terminals are gaining immense popularity thanks to their advanced and userfriendly features. Also, designing new compact antennas with good characteristics applied for 3G mobile terminals is quite necessary although number of similar studies had been conducted so far [1]. According to the federal communication commission (FCC) UWB rulings the signal is recognized as UWB if the signal frequency band is from $3.1 \mathrm{GHz}$ to $10.6 \mathrm{GHz}$ or the signal bandwidth is more than $500 \mathrm{MHz}$ [2].

An exponentially tapered slot antenna (ETSA) suitable for packaging and integration with other components is introduced and proposed for the UWB range with gain more than $5 \mathrm{dBi}$ and reflection coefficient below $-6 \mathrm{~dB}$ which represents VSWR $<3$ for the whole frequency range. The ETSA is a variation of the Vivaldi antenna, with the outer edge exponentially tapered, and it was introduced for the first time in [3]. The design and performance characteristics of the ETSA are investigated in [4].
Microstrip antennas have some attractive advantages such as small volume, very low-profile, light weight, easy fabrication, and constant directional radiation patterns, which have been widely used in designing miniaturized antennas. Since the development of tapered slot technology, many traditional antennas could be made into corresponding printed antennas, such as printed Vivaldi antennas [5] and printed log-periodic dipole antennas [6]. Figure 1 shows the geometry of the proposed antenna.

The Vivaldi antenna also demonstrates good performance, such as wide band and symmetric E- and H-plane beam patterns. The antenna was first proposed in [7]. Since then some advances have been made. In designs, fullwave numerical techniques and simulation tools are used to analyze the antenna. In applications, Vivaldi arrays were built for radar applications [8], wireless communications applications [9], and dual polarization applications [10]. Those multifunction applications are the current trends. The linearly polarized antenna shows good performance: reflection coefficient better than $<-6 \mathrm{~dB}$ and gain between 2.53 and $3.48 \mathrm{dBi}$ over the operating bandwidth in the DVB$\mathrm{T}$ band and about $4.4 \mathrm{dBi}$ in the WLAN band. This antenna has an end-fire radiation pattern when the parasitic element 


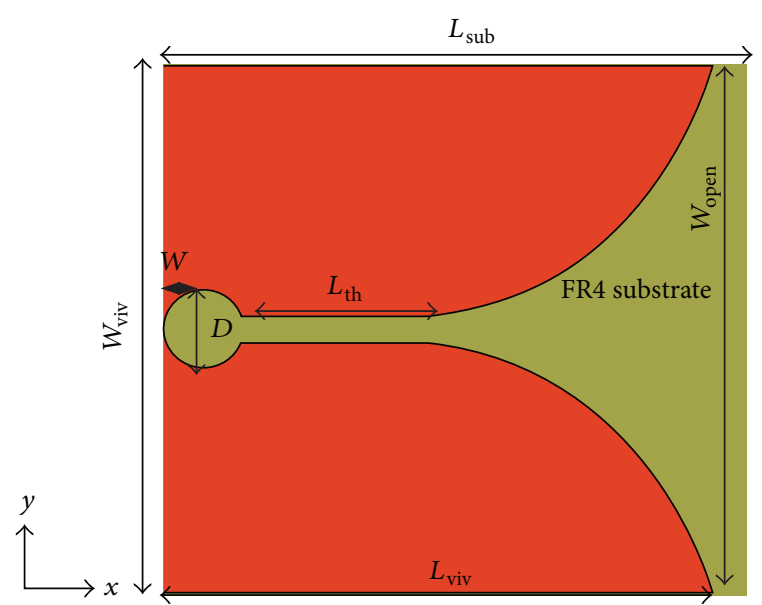

(a)

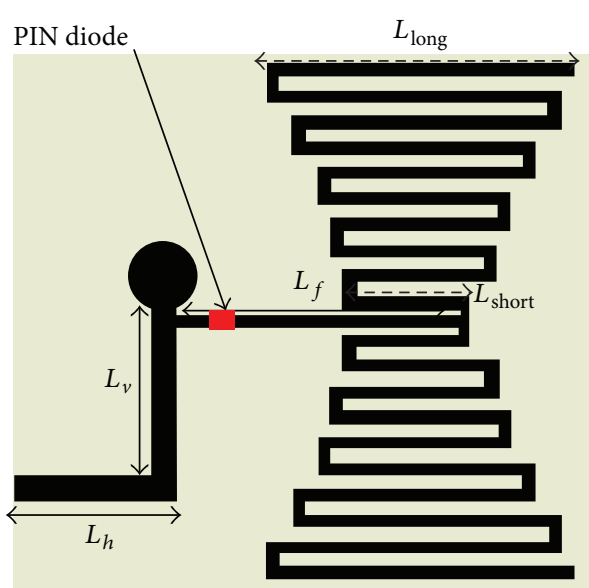

(b)

FIGURE 1: Geometry of the proposed antenna (a) upper layer and (b) lower layer.

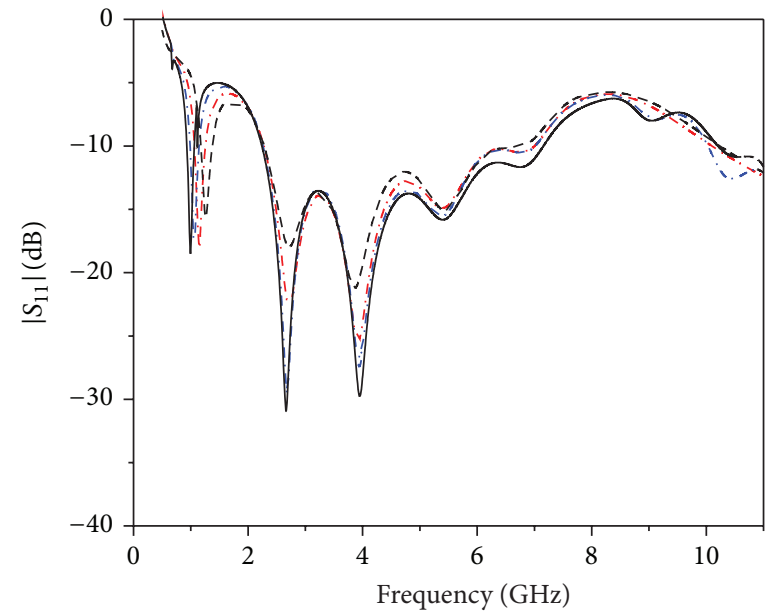

Effect of $D$

-- - $5 \mathrm{~mm}$

... $7 \mathrm{~mm}$

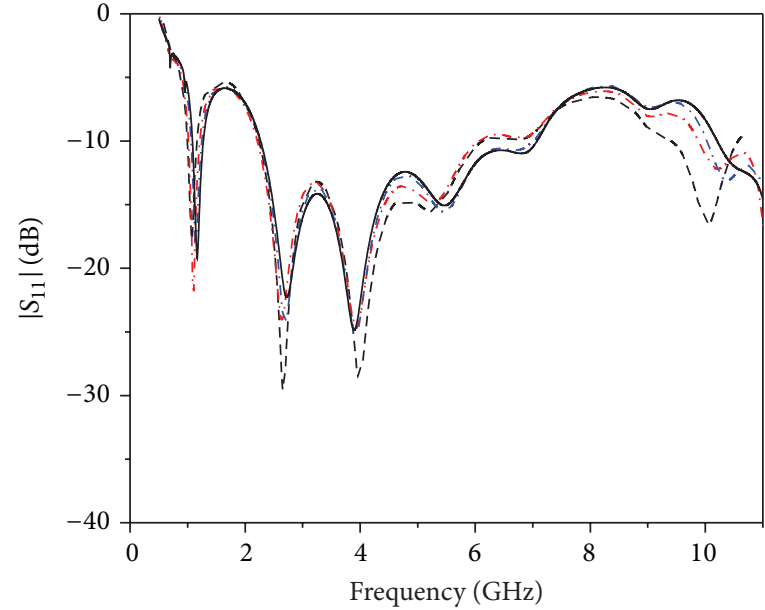

Effect of $W$

$---5 \mathrm{~mm}$

... $7 \mathrm{~mm}$

... $9 \mathrm{~mm}$

(a)

(b)
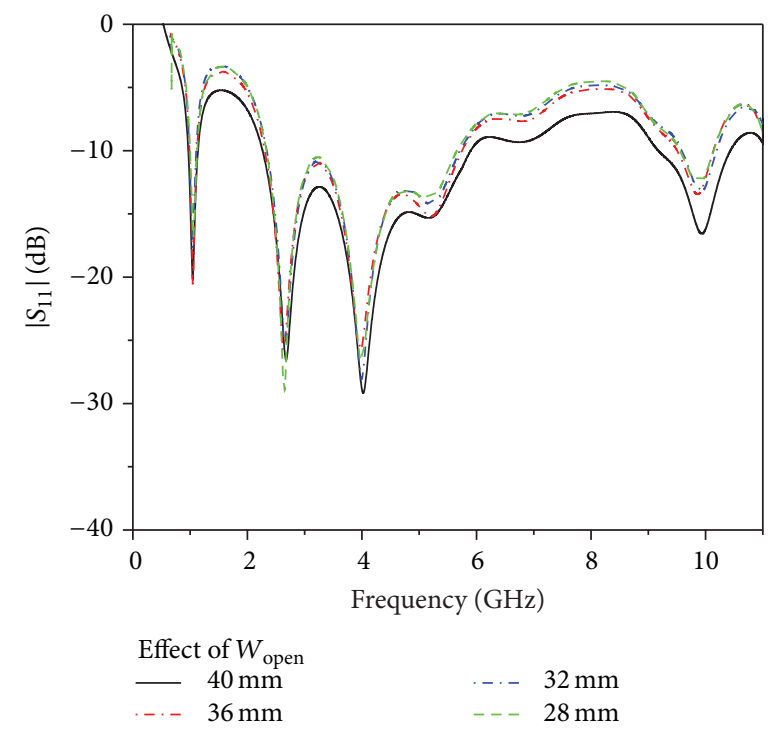

(c)

Figure 2: (a)-(c) The effect of diameter of the slot, backwall, and open end width, $D, W$, and $W_{\text {open }}$, respectively. 


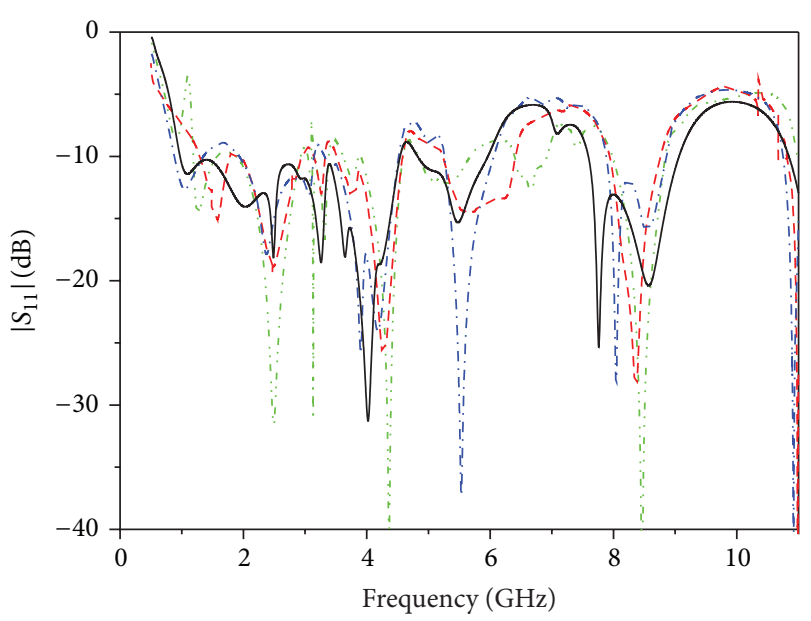

Effect of $L_{f}$

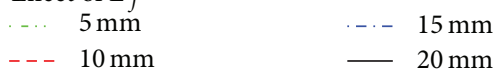

Figure 3: Effect of feeding position $\left(L_{f}\right)$.

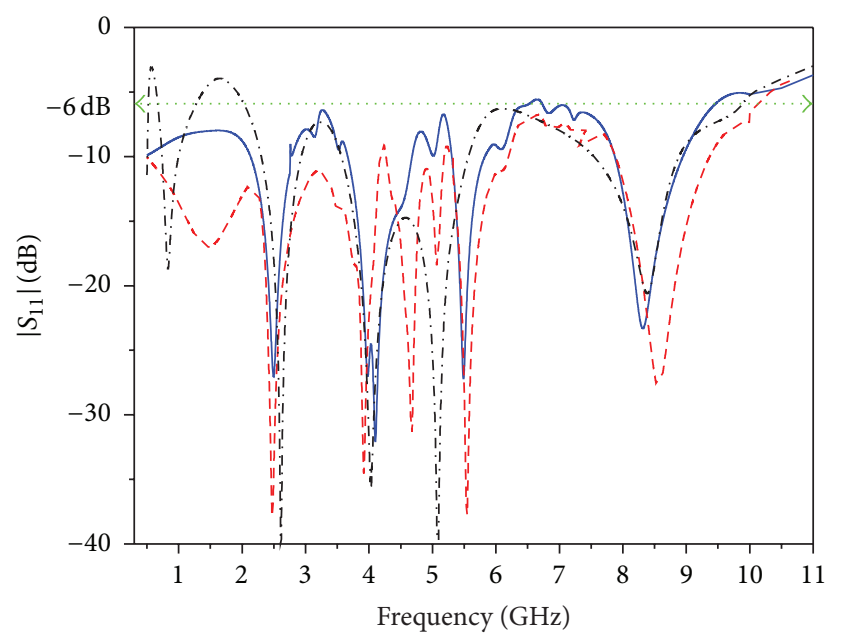

Design steps

...- Without parasitic

_ Without parasitic/SW off

- - - With parasitic/SW on

FIGURE 4: Simulated design step of the proposed antenna.

is disconnected and omniradiation pattern when the parasitic element is connected [11].

In this paper, a low-profile Vivaldi with parasitic meander line either connected or disconnected for added extra lower band is presented. The impedance bandwidth of the proposed antenna is ultrawide, with dimensions $0.52 \lambda_{L} \times 0.6 \lambda_{L}$ (where $\lambda_{L}$ is the wavelength at the lowest free space frequency) which is smaller compared with $0.762 \lambda_{L} \times 0.7 \lambda_{L}$ in [12]. PIN diode is used to switch the lower frequency band in addition to the high frequency band. This antenna operates over LTE bands, GSM1800 MHz/GSM1900 MHz, Bluetooth $2.4 \mathrm{GHz}$, WI-MAX frequency range (3-4) GHz, and W-LAN frequency range (5-6) GHz.

\section{Antenna Design and Configuration}

Figure 1 shows the geometry of the proposed Vivaldi antenna. According to $[13,14]$, the design parameters are dielectric constant and thickness of the substrate, conductor width, and the gap width of the slot. The Vivaldi is described by exponential function of the tapered slot-line as given in (1) and (2):

$$
\begin{aligned}
& y_{i}=\mp C_{i} \exp \left(R_{i} x\right), \\
& y_{i}= \pm 0.018 e^{(0.27 x),}
\end{aligned}
$$

where $y_{i}$ is the distance from the center line of the slot to the inner slot line. $c_{i}$ determines the line slot width at the feed port, $R_{i}$ specifies how the slot widens, and these values are given in (2). The feed port is located across the narrow slot, where a $50 \Omega$ coaxial line is connected; the location of the feed point is also important for impedance matching.

This section describes the design steps of the proposed Vivaldi antenna shown in Figure 1. For each step of the design, typical starting and ending values will be given. There are two influences in the optimized antenna design.

The first is the ground plane dimensions and the second is the feeding network dimensions. Exponential curvature can be changed with the value of parameter exponential rate $\left(R_{i}\right)$. First is the beginning of the taper, the second is the wide end of the taper. On both places, a reflection of the traveling wave is likely to occur. In the case of the beginning of the taper; reflection occurs with the initial change of the slot line width. Therefore, smoother taper in the throat length $(L \mathrm{th})$ minimizes the reflection there. Reflection at the wide end of the taper is connected to the fin termination and cannot be completely avoided. Changing exponential rate does not influence the wide end reflection significantly. The effect of balloon slot diameter $D$, backwall $W$, and open end width $W_{\text {Open }}$ are studied and optimized to improve the impedance bandwidth as shown in Figure 2.

Figure 2(a) shows that as the slot diameter increases the antenna bandwidth increases, reduces the lower frequency and improves the antenna matching; this is due to improve the impedance transition from $50 \Omega$ to air impedance while, by increasing the back-wall width $W$, increases the antenna reflection coefficient and reduces the bandwidth at high frequency. However, the width of open end decreases the antenna bandwidth and antenna matching. After optimizing the dimensions of the conventional Vivaldi antenna a parasitic meander line with different length is added and the position of this parasitic element is optimized under the antenna radiator to add lower frequency bands as shown in Figure 3 . Figure 3 shows that the effect of the parasitic element location $L_{f}$ is small on higher bandwidth and improves the bandwidth at lower frequency. The optimized dimensions are shown in Table 1.

The geometrical dimensions of the parasitic meandered shaped element are with width $1 \mathrm{~mm}$ and separation $1 \mathrm{~mm}$ with longest meandered length $24 \mathrm{~mm}$ and shortest meandered length $10 \mathrm{~mm}$. Ideal switch model is firstly used to imitate PIN diode switches with the open (OFF) and close (ON) states to switch the antenna from $450 \mathrm{MHz}$ to $2000 \mathrm{MHz}$ in 


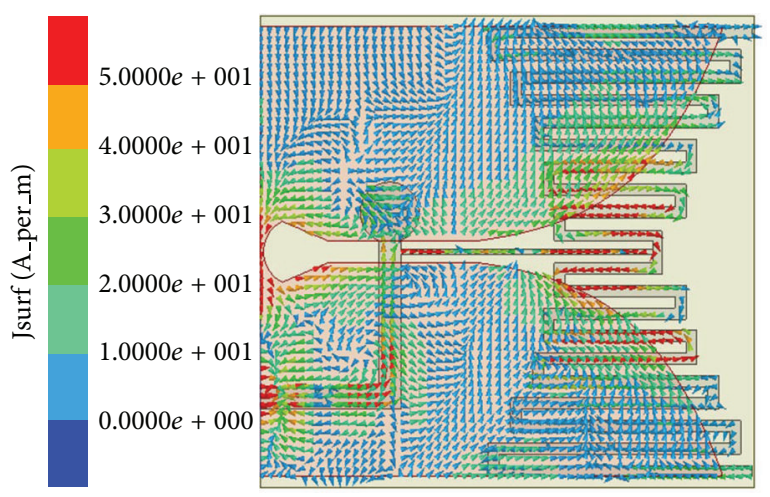

(a)

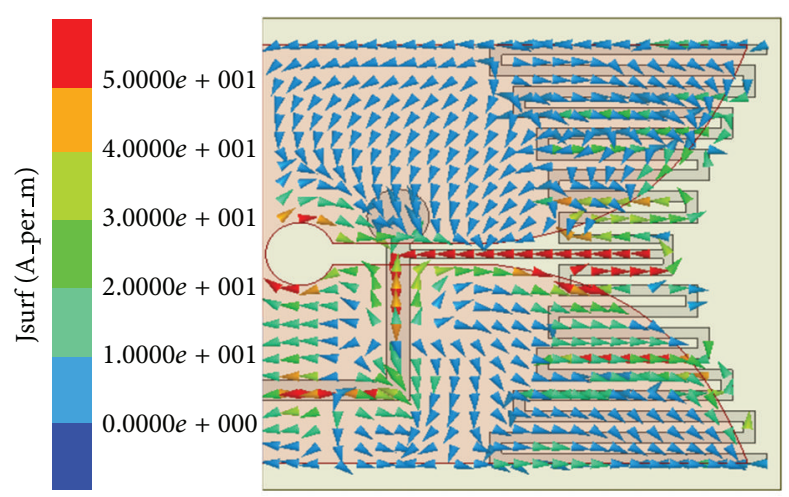

(b)
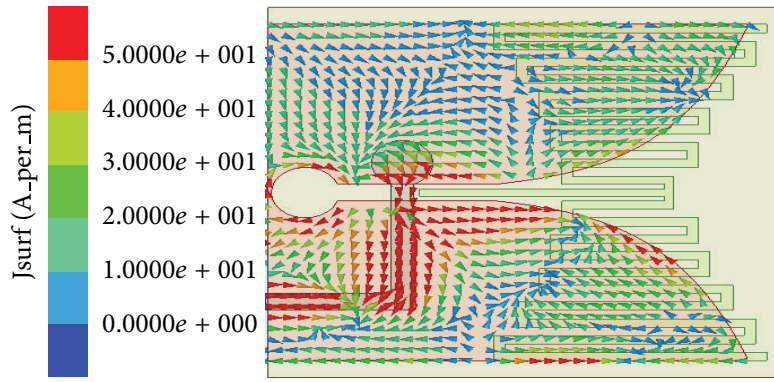

(c)

FIGURE 5: The current distribution at resonant frequencies (a) $0.5 \mathrm{GHz}$, (b) $2.5 \mathrm{GHz}$, and (c) $5.2 \mathrm{GHz} /(\mathrm{SW} \mathrm{ON})$.

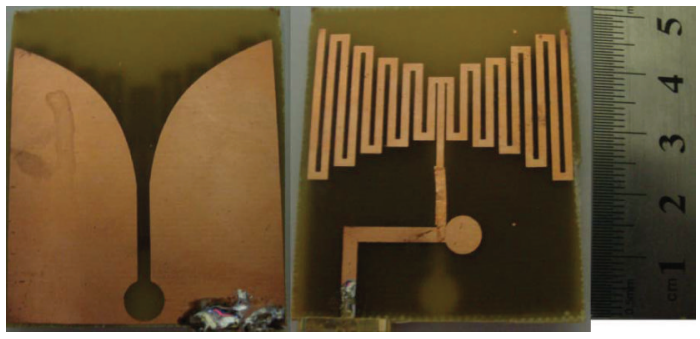

(a)

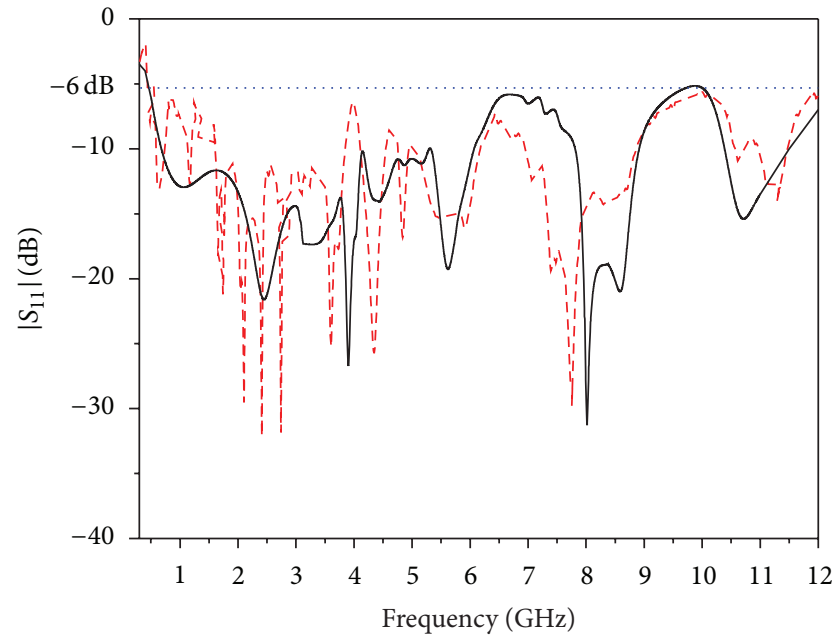

SW (on)

- _. Measured

— Simulated

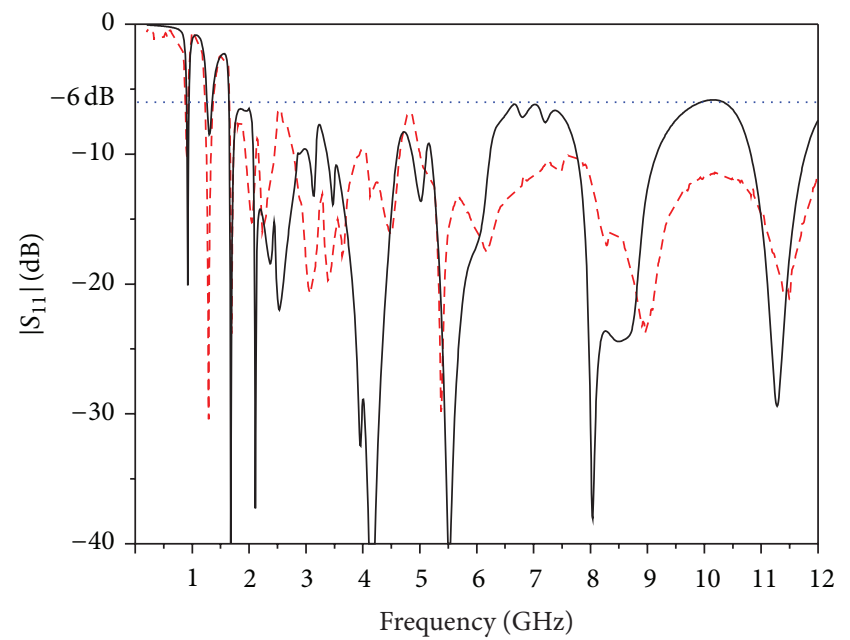

SW (off)

- - Measured

— Simulated

(b)

(c)

FIGURE 6: (a) The photo of the fabricated antenna, (b) comparison of simulated and measured $\left|S_{11}\right|$ with PIN (ON) mode, and (c) with PIN (OFF) mode. 


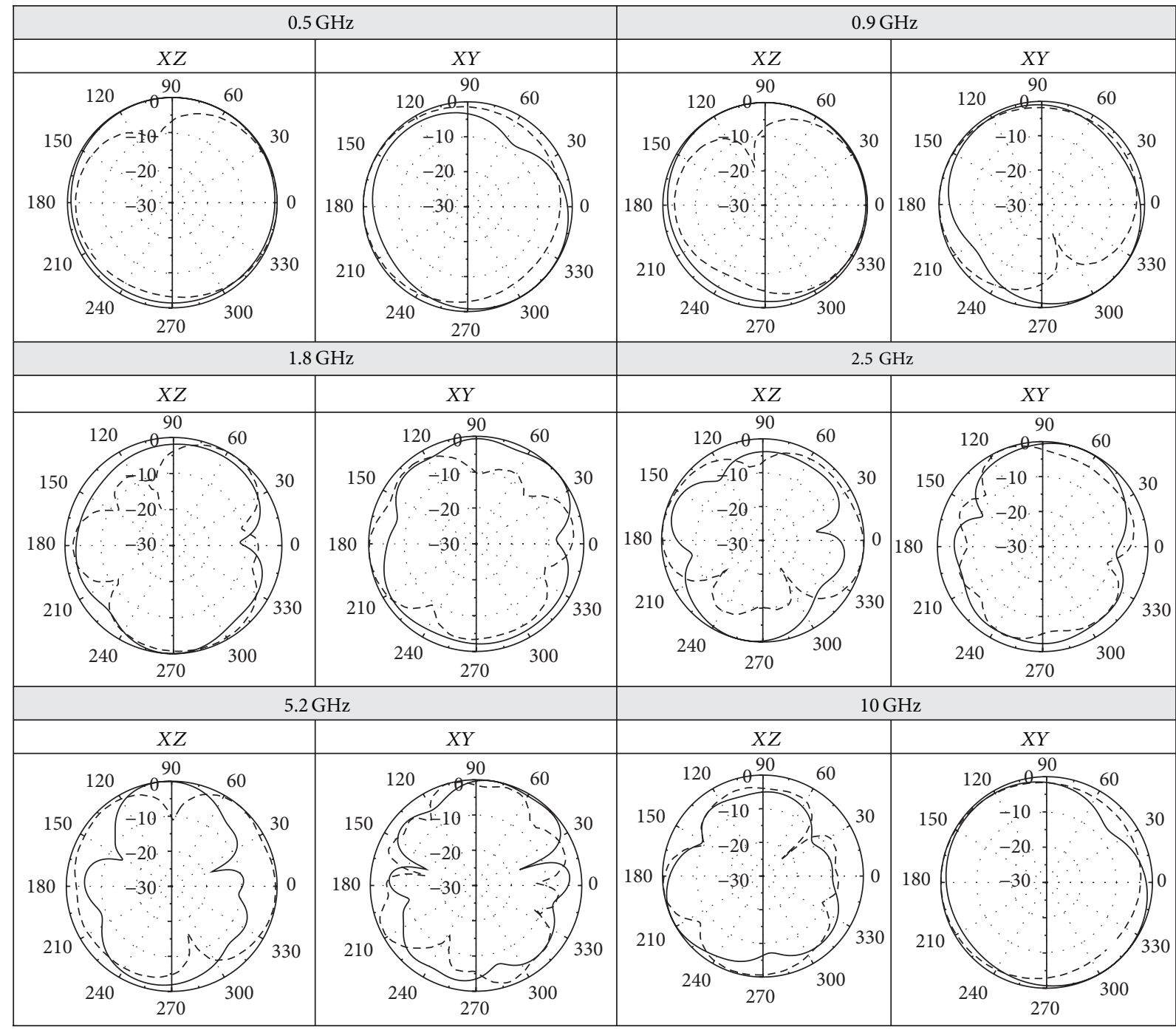

Figure 7: The simulated $2 \mathrm{D}$ radiation pattern at different resonant frequencies, $E_{\Phi}$ solid line and $E_{\theta}$ dash line.

TABLE 1: The antenna dimensions (in $\mathrm{mm}$ ).

\begin{tabular}{lccccccccc}
\hline$L_{\text {Sub }}$ & $W_{\text {viv }}$ & $L_{f}$ & $L_{\text {th }}$ & $w$ & $L_{\text {viv }}$ & $W_{\text {open }}$ & $D$ & $L_{v}$ & $L_{h}$ \\
\hline 45 & 40 & 2 & 14 & 0.5 & 40 & 40 & 6 & 13 & 12 \\
\hline
\end{tabular}

addition to the basic bandwidth, which is extended from $2.5 \mathrm{GHz}$ to $10 \mathrm{GHz}$ with total $75 \%$ size reduction as compared to the original Vivaldi size. The open (OFF) and close (ON) states of the switches are simulated in the absence or presence of a metal pad with the area $W_{\mathrm{sw}} \times L_{\mathrm{sw}}=0.3 \times 0.9 \mathrm{~mm}^{2}$, respectively [15-17]. This is approximately the same area of a real PIN diode switch. Then the practical model of the PIN diode HPND-4005 is used as forward biased with $0.7 \mathrm{~V}$ and $10 \mathrm{~mA}$. It exhibits an ohmic resistance of $3 \Omega$ and intrinsic capacitance of $0.1 \mathrm{pF}$ for forward bias while exhibits $2.7 \mathrm{Kohm}$ and $9 \mathrm{pF}$ at $0 \mathrm{~V} .10 \mathrm{pF}$ capacitors are used to isolate the RF signal from the DC and RF choke coil MCL 50$10000 \mathrm{MHz}$.

PIN diode is added as shown in Figure 1(b) (red) to add a lower band which is extended from $450 \mathrm{MHz}$ to
$2000 \mathrm{MHz}$ with main impedance bandwidth which extended from $2.5 \mathrm{GHz}$ to $10 \mathrm{GHz}$ as shown in Figure 4.

\section{Measured Results and Discussion}

A prototype has been fabricated using photolithographic technique and its reflection coefficient was measured using vector network analyzer ES8719. It was simulated using HFSS electromagnetic simulator based on the finite element method. The substrate material is FR4 with dielectric constant 4.7, dielectric height $=1.6 \mathrm{~mm}$, and loss tangent $\tan \delta=$ 0.02 . The total area of the antenna is $40 \times 44 \mathrm{~mm}^{2}\left(0.52 \lambda_{L} \times\right.$ $\left.0.6 \lambda_{L}\right)$. By carefully tuning, optimized design parameters are obtained. Commercial FR4 was used because it resists high heat and has excellent chemical and mechanical properties. 
International Journal of Antennas and Propagation

TABLE 2: The simulated antenna parameters at resonant frequencies of three turns meander shaped-slot (SW/ON/OFF modes).

\begin{tabular}{|c|c|c|c|c|c|c|}
\hline Resonance frequency. (GHz) & 0.5 & 0.9 & 1.8 & 2.5 & 5.2 & 10 \\
\hline Gain $(\mathrm{dBi})$ & 1.5 & 1.8 & 2.7 & 2.9 & 4 & 5.5 \\
\hline Sim. radiation efficiency (\%) & 80 & 85 & 90 & 83 & 95 & 75 \\
\hline Mea. radiation efficiency (\%) & 70 & 75 & 82 & 75 & 85 & 68 \\
\hline
\end{tabular}

The current distribution at resonant frequencies $500 \mathrm{MHz}$, $2 \mathrm{GHz}$, and $5.2 \mathrm{GHz}$ is shown in Figure 5.

Figure 6(a) shows a photo of fabricated antenna, while $\left|S_{11}\right|$ of both PIN diode modes (ON/OFF) is shown in Figures 6(b) and 6(c). The experimental results reasonably agree with the simulated ones and the impendence bandwidth is extended from $450 \mathrm{MHz}$ to $12 \mathrm{GHz}$.

It is clear that very wide-band impedance matching is achieved. The far-field radiation patterns are simulated; the normalized patterns are tabulated at resonant frequencies of $500 \mathrm{MHz}, 900 \mathrm{MHz}, 1.8 \mathrm{GHz}, 2.5 \mathrm{GHz}, 5.2 \mathrm{GHz}$, and $10 \mathrm{GHz}$ in Figure 7. It can be seen that at low frequency band, the patterns are much similar to that of a dipole. Because the effective region is located at the top of the antenna, the bottom part has little effects on the radiation. At medium and high frequency bands, the patterns behave more directive. Because the effective region is moved to the middle part, the bottom part acts as a reflector. The comparison between measured and simulated radiation efficiency is shown in Table 2, which varies from $65 \%$ to $95 \%$ with average value of $80 \%$.

\section{Conclusion}

A Vivaldi antenna with parasitic meander shape for DVPT and UWB applications has been presented in this paper. The antenna bandwidth extends from $450 \mathrm{MHz}$ to $12 \mathrm{GHz}$ with $\left|S_{11}\right|<-6 \mathrm{~dB}$. The PIN diode is connected to add and remove the UHF band which extends from 450 to $1.5 \mathrm{GHz}$ frequency. The proposed antenna is compact with $0.52 \lambda_{L} \times 0.6 \lambda_{L} \mathrm{~mm}^{2}$ and there is very good agreement between measured and simulated results. The antenna gain varies from $1.5 \mathrm{dBi}$ to $5.5 \mathrm{dBi}$ over the operating band with $80 \%$ average radiation efficiency. The proposed antenna can radiate omnidirectional patterns at all the operating frequency bands which makes it suitable for use in wireless communication applications.

\section{Conflict of Interests}

The authors declare that there is no conflict of interests regarding the publication of this paper.

\section{Acknowledgment}

This research is supported by the National Telecommunication Regularity Authority (NTRA), Ministry of Communication and Information Technology, Egypt.

\section{References}

[1] FCC, FCC First Report and Order on Ultra-Wideband Technology, 2002.
[2] "ECC Decision of 24 March 2006 on the Harmonised Conditions for Devices using Ultra-Wideband (UWB) Technology in Bands below 10.6 GHz," 2006, http://www.ero.dk/.

[3] M. C. Greenberg and L. L. Virga, "Characterization and design methodology for the dual exponentially tapered slot antenna," in Proceedings of the IEEE Society International Symposium on Antennas and Propagation, vol. 1, pp. 88-91, Atlanta, Ga, USA, July 1999.

[4] M. C. Greenberg, K. L. Virga, and C. L. Hammond, "Performance characteristics of the Dual Exponentially Tapered Slot Antenna (DETSA) for wireless communications applications," IEEE Transactions on Vehicular Technology, vol. 52, no. 2, pp. 305-312, 2003.

[5] J. D. S. Langley, P. S. Hall, and P. Newham, "Balanced antipodal vivaldi antenna for wide bandwidth phased arrays," IEE Proceedings on Microwaves, Antennas and Propagation, vol. 143, no. 2, pp. 97-102, 1996.

[6] C. Yu, W. Hong, C. Yu, Z. Q. Kuai, and W. Qin, "Bandnotched UWB printed log-periodic dipole antenna fed by half mode substrate integrated waveguide," in Proceedings of the International Symposium Antennas and Propagation (ISAP '09), Thailand, October 2009.

[7] K. F. Lee and W. Chen, Advances in Microstrip and Printed Antennas, John Wiley \& Sons, 1997.

[8] J. L. Jordan, C. Chevalier, and G. E. Ponchak, "Characteristics of corrugated double exponentially tapered slot antenna," in Proceedings of the IEEE Antennas and Propagation Society International Symposium, pp. 2575-2578, 2006.

[9] N. H. M. Sobli and H. E. Abd-El-Raouf, "Design of a compact band-notched antenna for ultrawideband communication," in Proceedings of the IEEE Antennas and Propagation Society International Symposium (AP-S '08), San Diego, Calif, USA, July 2008.

[10] J. J. Lee, S. Livingston, and R. Koenig, "Performance of a wideband (3-14 GHz) dual-pol array," in Proceedings of the IEEE International Symposium on Antennas and Propagation, vol. 1, pp. 551-554, June 2004.

[11] D. C. Thompson, O. Tantot, H. Jallageas, G. E. Ponchak, M. M. Tentzeris, and J. Papapolymerou, "Characterization of Liquid Crystal Polymer (LCP) material and transmission lines on LCP substrates from 30 to $110 \mathrm{GHz}$," IEEE Transactions on Microwave Theory and Techniques, vol. 52, no. 4, pp. 1343-1352, 2004.

[12] D. M. Elsheakh and E. A. Abdallah, "Novel shapes of Vivaldi antenna for Ground Penetrating Radar (GPR)," in Proceedings of the 7th IEEE European Conference on Antennas and Propagation (EuCAP '13), Gothenburg, April 2013.

[13] A. H. Mohammadian, A. Rajkotia, and S. S. Soliman, "Characterization of UWB transmit-receive antenna system," in Proceedings of the IEEE Conference on Ultra Wideband Systems and Technologies, pp. 157-161, 2003.

[14] S. Licul, J. A. N. Noronha, W. A. Davis, D. G. Sweeney, and T. M. Bielawa, "A parametric study of time-domain characteristics of possible UWB antenna architectures," in Proceedings of the 58th 
IEEE Vehicular Technology Conference (VTC '03), vol. 5, pp. 3110-3114, October 2003.

[15] F. A. Tarboush, R. Nilavalan, S. W. Cheung et al., "Compact printed multiband antenna with independent setting suitable for fixed and reconfigurable wireless communication systems," IEEE Transactions on Antennas and Propagation, vol. 60, no. 8, pp. 3867-3874, 2012.

[16] H. F. Abutarboush, R. Nilavalan, S. W. Cheung et al., "A reconfigurable wideband and multiband antenna using dual-patch elements for compact wireless devices," IEEE Transactions on Antennas and Propagation, vol. 60, no. 1, pp. 36-43, 2012.

[17] Y. Cai, Y. J. Guo, and A. R. Weily, "A frequency-reconfigurable quasi-Yagi dipole antenna," IEEE Antennas and Wireless Propagation Letters, vol. 9, pp. 883-886, 2010. 

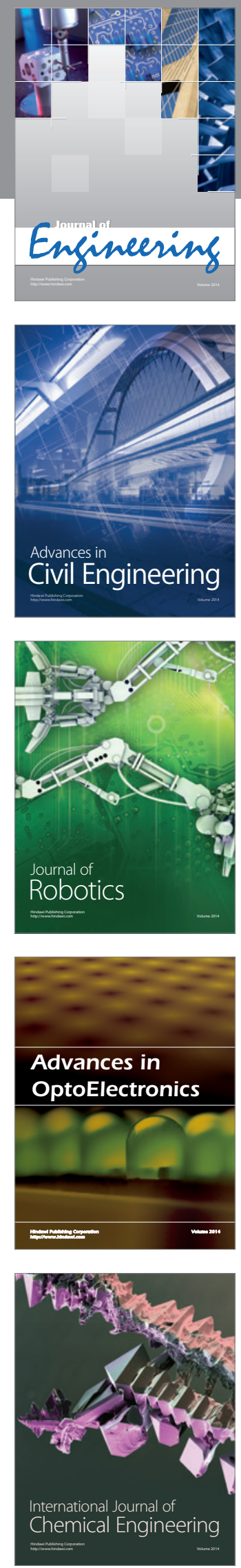

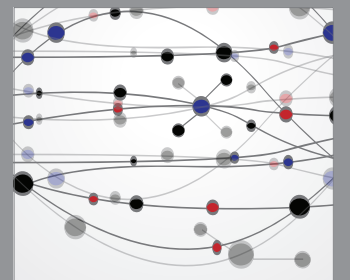

The Scientific World Journal
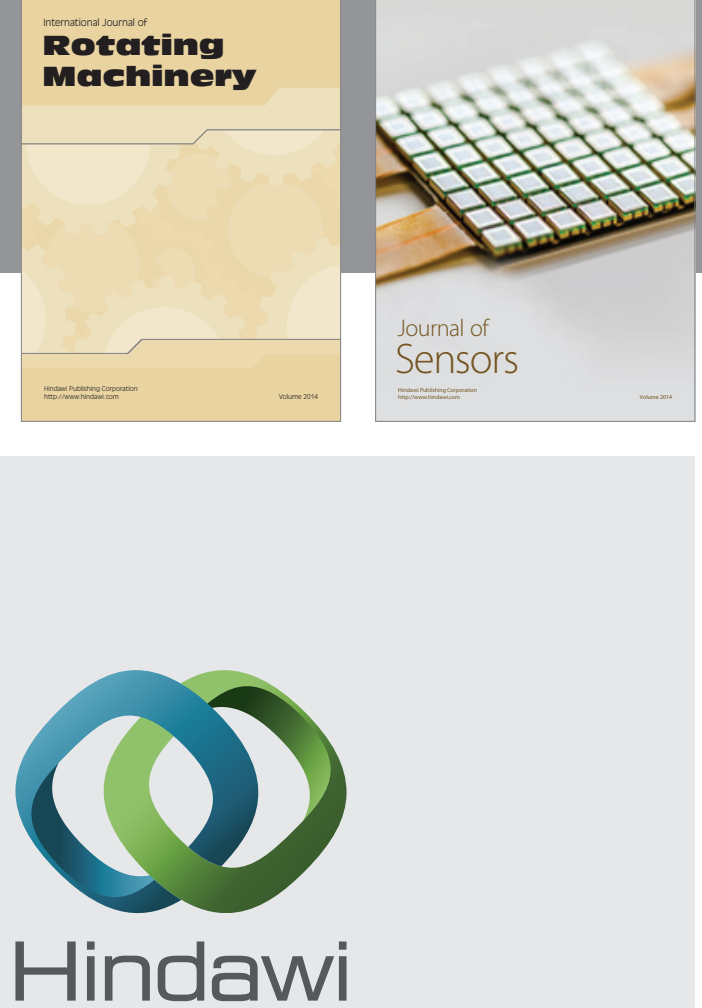

Submit your manuscripts at http://www.hindawi.com
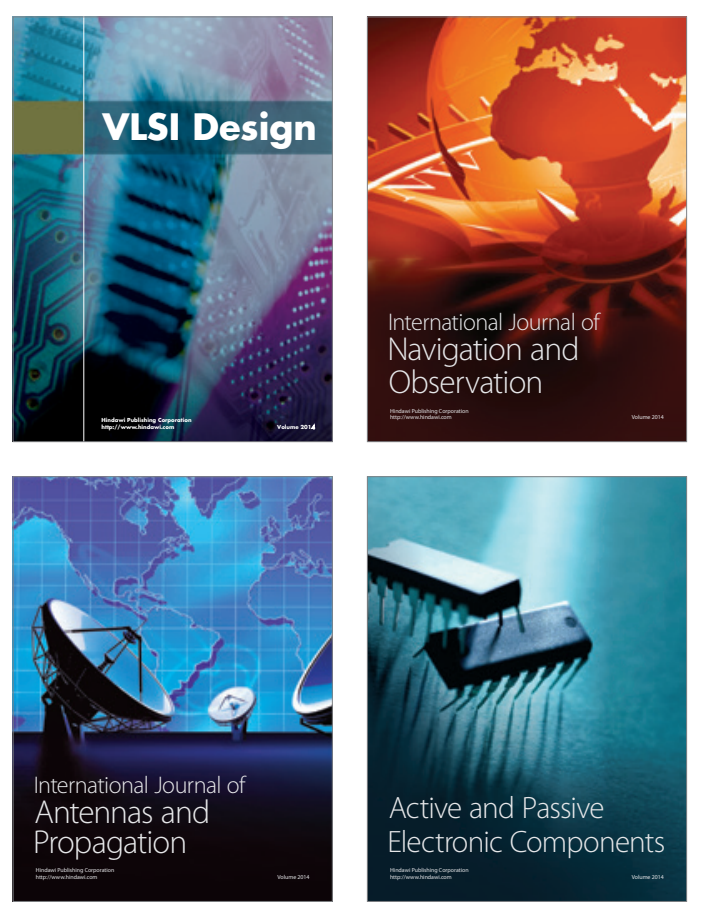
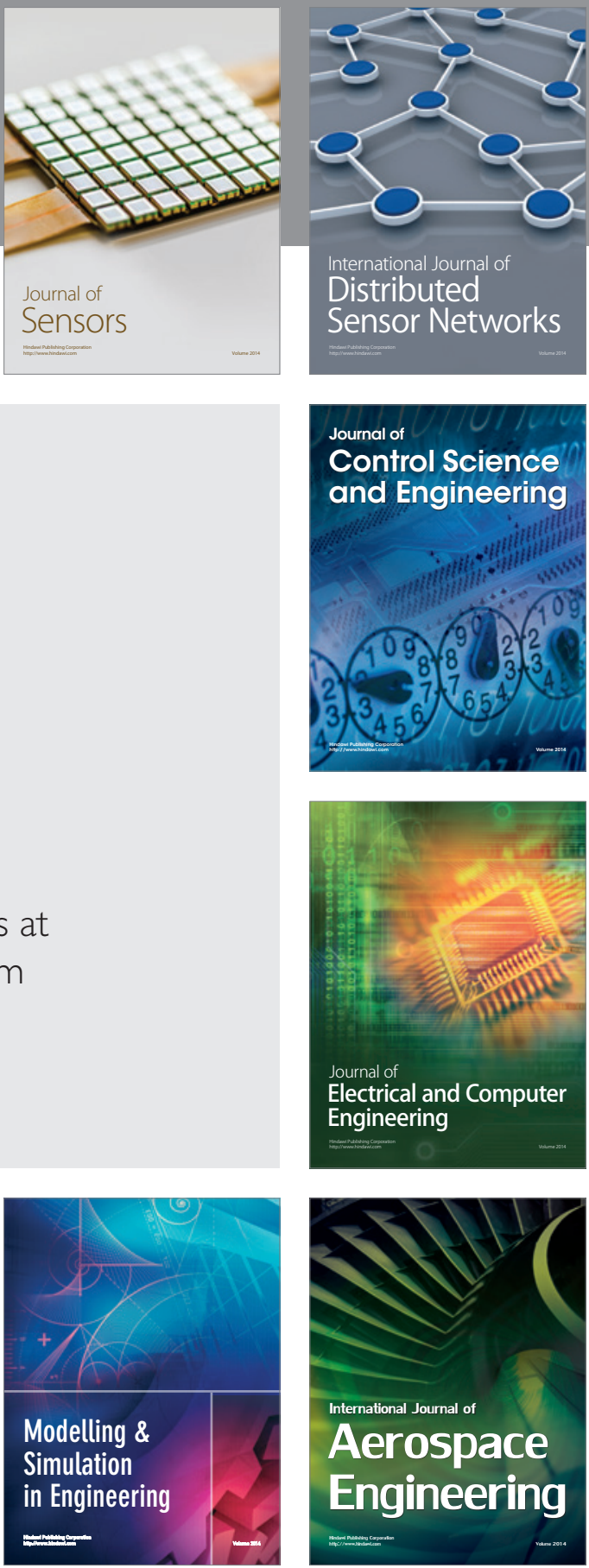

Journal of

Control Science

and Engineering
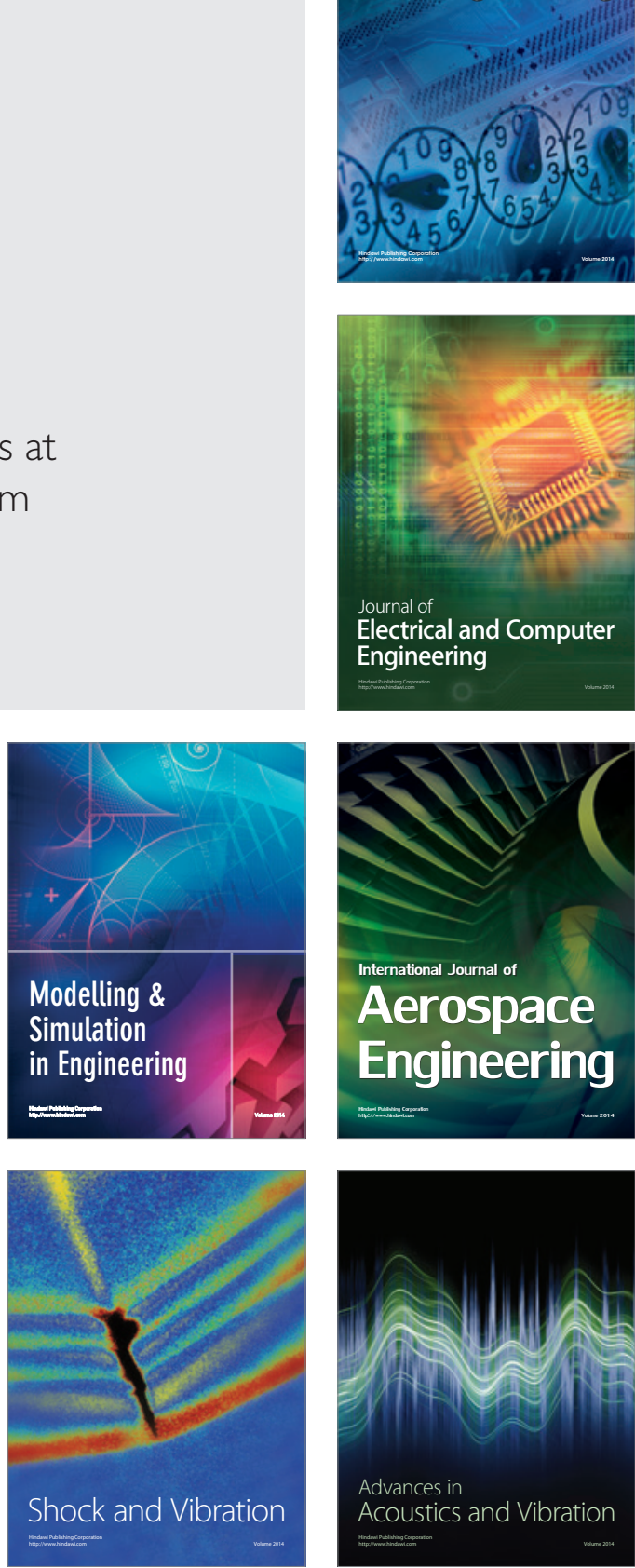